\title{
Effects of seminal vesicle fluid components on sperm motility in the house mouse
}

\author{
Betsy Peitz
}

Biology Department, California State University-Los Angeles, Los Angeles, CA 90032, U.S.A.

\begin{abstract}
Summary. Fluid obtained by stripping dissected seminal vesicles was mixed with phosphate-buffered saline and the soluble proteins were separated by gel filtration on BioRad P150 into 4 fractions. Fractions were collected and concentrated using an Amicon ultrafiltration system using YM2 membranes with a molecular weight cut-off of 1000 . Epididymal sperm suspensions were incubated in medium containing one of the 4 fractions or $1 \mathrm{mg} \mathrm{BSA} / \mathrm{ml}$, or no added protein. After incubation for $2 \mathrm{~h}$ the motility of the spermatozoa in each suspension was assessed by a videomicrographic procedure. Two aspects of motility, velocity and the shape of the swimming path, were monitored. The results indicate that the seminal vesicles produce at least three factors that influence sperm motility. Fraction $3\left(M_{\mathrm{r}} 12000-24000\right)$ was detrimental to motility; after incubation for $2 \mathrm{~h}$ almost all the spermatozoa were immotile. Fractions 2 $\left(M_{\mathrm{r}} 25000-40000\right)$ and $4\left(M_{\mathrm{r}} 7000-12000\right)$ both influenced the shape of the swimming path: spermatozoa incubated in Fraction 2 had straighter trajectories while those incubated in Fraction 4 showed more progressive paths with less side-to-side movement of the head about the path. These effects of factors from the seminal vesicle fluid on sperm motility may influence the way in which the spermatozoa move in the female reproductive tract and could help to explain why removal of the seminal vesicles reduces fertility in the mouse.
\end{abstract}

Keywords: sperm motility; seminal vesicles; accessory glands; mouse

\section{Introduction}

The successful use of epididymal spermatozoa for artificial insemination and in-vitro fertilization in a number of species has led to a general belief that the seminal plasma is not important for fertility. On the other hand, removal of the seminal vesicles, which contribute the bulk of seminal plasma in rodents, reduced fertility in house mice (Pang et al., 1979; Peitz \& Olds-Clarke, 1986) and rats (Queen et al., 1981). Although removal of the seminal vesicles eliminates the formation of the vaginal plug, this does not explain the reduced fertility since removal of the coagulating glands, which also prevents the formation of the vaginal plug, did not reduce fertility (Pang et al., 1979). Since the absence of a vaginal plug does not explain the decrease in fertility, it indicates that the seminal vesicles contribute some factor, in addition to the plug, which is involved in maintaining fertility after natural mating.

The accessory glands produce factors which influence the motility of spermatozoa and the influence of the seminal plasma on sperm motility varies between species; in some, seminal plasma promotes motility (rat: Morita \& Chang, 1971; man: Lindholmer, 1974), while in others it is detrimental (bull, rabbit and ram: Dott et al., 1979). There are also variations in seminal effects on spermatozoa between individuals of a single species (Rozin, 1960; Cohen et al., 1982). Since semen is a complex mixture, containing components from several glands (Mann \& Lutwak-Mann, 1981), 
it may have several effects on spermatozoa (Baas et al., 1983). The relative role of components from the individual accessory glands in the control of sperm motility is unclear.

Videomicrographic analysis of the motility of spermatozoa collected from the uterus after matings with males from which the seminal vesicles had been removed indicated that the seminal vesicles influence the pattern of sperm motility in the house mouse (Peitz \& Olds-Clarke, 1986). Since sperm motility is necessary for fertility the altered motility may account for this reduction in fertility. The seminal vesicle fluids could protect the spermatozoa from the influence of factors from the other male accessory glands (prostate and coagulating glands) and the uterus, or could have a direct effect on sperm motility.

The purpose of this study was to determine whether factors from the seminal vesicle of the house mouse have a direct effect on sperm motility in vitro. In addition, this study was undertaken as a first step towards isolating the seminal vesicle components that influence sperm motility in the house mouse.

\section{Materials and Methods}

Animals. Two strains of mice were used; a hybrid strain, the F1 offspring of matings of two inbred strains, $\mathrm{C} 57 \mathrm{BL} / 6$ and $\mathrm{C} 3 \mathrm{H} / \mathrm{HeJ}$, and an outbred strain, CF-1 (Charles Rivers). All males used were at least 3 months old.

Preparation of seminal vesicle protein fractions. The seminal vesicles from 2 males were dissected and their secretions expressed into $2 \mathrm{ml}$ phosphate-buffered saline (PBS: Gibco Laboratories, Grand Island, NY 14072). The resulting suspension was chilled for $30 \mathrm{~min}$ then centrifuged at $1000 \mathrm{~g}$ for $10 \mathrm{~min}$ to remove insoluble material. The supernatant was applied to a $1 \mathrm{~m}$ column of BioRad P150 gel (BioRad Chemical Division, Richmond, CA 94804) and eluted with PBS at a flow rate of $4-5 \mathrm{ml} / \mathrm{h}$ in a cold room at $4-6^{\circ} \mathrm{C}$. The separation of the proteins was monitored by determining the optical density of the effluent at $280 \mathrm{~nm}$. The column was calibrated using BioRad molecular weight standards.

Generally the effluent showed 4 peaks with molecular weight $>7000$. The fluid in the tubes containing each of these 4 fractions was pooled and concentrated to about $2 \mathrm{ml}$ using an Amicon ultrafiltration system (Amicon Corp., Danvers, MA 01923) and YM2 membranes with a molecular weight cutoff of 1000. Each fraction was further concentrated to $0.3-0.5 \mathrm{ml}$ by centrifugation in Amicon Centricon tubes with a molecular weight cutoff of 10000 . This 2 -step concentration procedure was used in an attempt to achieve the highest concentration possible for each fraction so that the influence of the fractions would not be missed because of too little protein in the solution. These procedures achieved a maximum concentration about 50 times the concentration in the column effluent. The final concentration of protein in each fraction was determined using the BioRad dye-binding protein assay with bovine serum albumin (BSA) as a standard.

Incubation medium. Spermatozoa were suspended and incubated in a modified Krebs-Ringer-bicarbonate medium (KRB) that would support in-vitro fertilization. This medium was prepared by adding the following components to $100 \mathrm{ml}$ distilled water (Flow Laboratories, McLean, VA 22102 ): $0.5605 \mathrm{~g} \mathrm{NaCl}, 0.0447 \mathrm{~g} \mathrm{KCl}, 0.025 \mathrm{~g}$ $\mathrm{CaCl}_{2} .2 \mathrm{H}_{2} \mathrm{O}, 0.0049 \mathrm{~g} \mathrm{NaH}_{2} \mathrm{PO}_{4}, 0.029 \mathrm{~g} \mathrm{MgSO}_{4} .7 \mathrm{H}_{2} \mathrm{O}, 0.2106 \mathrm{~g} \mathrm{NaHCO}_{3}, 0 \cdot 1$ g glucose, $0.006 \mathrm{~g}$ penicillin, $0.0112 \mathrm{~g}$ sodium pyruvate, $0.005 \mathrm{~g}$ streptomycin and $0.44 \mathrm{ml}$ sodium lactate. The concentrated seminal vesicle proteins in PBS were mixed 1:1 with another version of this medium $(2 \times \mathrm{KRB})$ containing twice the amount of all the components except $\mathrm{NaCl}$, which was added at the regular amount, and $\mathrm{NaHPO}_{4}$ which was omitted. The final concentration of all the components in the medium containing the seminal vesicle proteins was the same as in the medium containing the spermatozoa. Two control solutions were also prepared. The first was made by dissolving $2 \mathrm{mg}$ BSA (Pentax, fatty acid-free: ICN Immunobiological, Lisle, IL 60532)/ml in PBS then mixing this solution $(1: 1 \mathrm{v} / \mathrm{v})$ with $2 \times \mathrm{KRB}$. The second had no added protein and was prepared by mixing PBS (l:1 v/v) with $2 \times \mathrm{KRB}$. The concentrated fractions from each of 4 columns were tested for their effect on the motility of epididymal spermatozoa from one male of the same strain for each of the two strains of mice. For some of the CF-1 studies equal volumes of the 4 fractions were mixed and then diluted with $2 \times \mathrm{KRB}$ to test for interactions between the protein fractions.

Sperm preparation. Each cauda epididymidis from 1 male was dissected out and cut in several places then placed in $200 \mu \mathrm{l} \mathrm{KRB}$ for $10 \mathrm{~min}$ to allow the spermatozoa to swim out. The intact tissue pieces were removed and $25 \mu \mathrm{l}$ samples of the remaining sperm suspension were mixed with $75 \mu \mathrm{l}$ of the concentrated fractions suspended in media as described above. Aliquants of sperm suspension were also mixed with the BSA and protein-free control solutions. This provided a means of testing all the fractions and control solutions on spermatozoa from a single population. The sperm suspensions in concentrated fractions and control solutions were incubated under oil for $2 \mathrm{~h}$ at $37^{\circ} \mathrm{C}$ in $5 \% \mathrm{CO}_{2}$ in air.

Motility analysis. Videotapes of spermatozoa that had been incubated with each of the fractions and control solutions were made as described by Olds-Clarke (1986) and Tessler \& Olds-Clarke (1985). The videotapes were analysed by the methods of Tessler \& Olds-Clarke (1985). Mean values for two types of measures were calculated for 15 individual freely motile spermatozoa chosen at random from each sample. Three of the calculated measures 
describe the shape of the sperm trajectory (Tessler \& Olds-Clarke, 1985). The linear index (LI) provided an estimate of how straight the trajectory was. Straight-swimming spermatozoa have LI values close to $1 \cdot 0$. Spermatozoa moving with no preferred direction have low values for LI. The curvilinear progressiveness ratio (PRc) is an inverse index of the variation in movement around the trajectory. For straight-swimming spermatozoa it is an estimate of the relative amplitude of the side-to-side movement of the sperm head about the trajectory. Higher values indicate less side-to-side head movement. The progressiveness ratio (PR) (Overstreet et al., 1979) is an index of the relative amount of forward movement during the observation period. For a perfectly straight path $P R=1$. Spermatozoa which exhibit no preferred direction of motion or move back and forth within a small area have low values for PR.

The other two measures were of the velocity of the spermatozoa. The curvilinear velocity $(\mathrm{Vc})$ is the total real-time speed of the head-midpiece junction. The coefficient of variation of move length (CVML) was developed to quantify changes in the swimming speed of individual spermatozoa with time (Olds-Clarke, 1986). Those spermatozoa that move at the same speed throughout the observation period have low CVML values, while those that slow down and speed up again during swimming have higher values for this measure.

The percentage of motile cells after incubation was assessed directly from the videotapes for each sample using the method described by Katz \& Overstreet (1981) with one modification. Instead of counting the first 5 spermatozoa on a diagonal for each taping region, all the normal cells in the first frame in good focus for a given taping region were marked and counted before and after advancing the videotape. The percentage was then calculated from the pooled values for all the fields examined. This method was used instead of counting the percentage motility from a haemocytometer because doing both a count and a taping for each sample would have taken so long that the incubation times would not have been comparable for all the samples. The accuracy of the method was compared to standard motility counts from a haemocytometer for 12 sperm samples ( 6 from each strain of mice) incubated in medium with no proteins added. The percentage motility values determined by the two methods were not significantly different from each other: $46.0 \pm 3.96 \%$ by the haemocytometer method and $39 \cdot 2 \pm 4.88 \%$ by the tape method.

All statistical analyses followed Sokal \& Rohlf (1969). The values for the treatment groups were tested for significant differences by non-parametric tests (Kruskal-Wallis and Wilcoxon tests). Values for the motility measures of spermatozoa incubated in seminal vesicle fractions were compared to the values for spermatozoa incubated in BSA and media with no added proteins. Non-parametric statistics were used because in most cases the variances were not homogeneous and in some cases the values were not normally distributed. This was particularly true for the Linear Index which does not show a normal distribution even with much larger sample sizes (Tessler \& Olds-Clarke, 1985).

\section{Results}

\section{Seminal vesicle protein fractions}

Gel filtration separates the seminal vesicle fluid into several discrete fractions. The profile was essentially the same as that reported previously for gel filtration using Sephadex G-100 (Peitz \& Bennett, 1981): Fraction 1 included all the material with $M_{\mathrm{r}}>50000$, Fraction 2 included substances of $M_{\mathrm{r}} 25000-40000$, Fraction 3 substances of $M_{\mathrm{r}} 12000-24000$, and Fraction 4 those of $M_{\mathrm{r}} 7000-12000$. There were no obvious differences in the shape of the profile between the 2 strains of mice used, but there was some variability in the relative size of the peaks from sample to sample, especially in Peak 2. In general the peak height and the concentration of recovered protein in Fractions 2, 3 and 4 were higher from columns with seminal vesicle proteins from outbred males than from hybrid males. Protein recovery after concentration was best for Fraction 1 . The lower molecular weight fractions had a tendency to stick to the membranes and reduce their efficiency, especially in the centrifugation step with the Amicon Centricon tubes. Taking into account the amount of dilution during gel filtration and the final volume after ultrafiltration, the final concentration of the proteins was probably between 1 and 5 times their concentration in the original seminal vesicle fluid suspension.

\section{Effects of seminal vesicle protein fractions on sperm motility}

The effects of seminal vesicle components on percentage motility and velocity are presented in Table 1 and the effects on path shape are presented in Table 2. Comparison of the data in Tables 1 and 2 indicates that Fraction 3 was inhibitory in both strains while Fraction 2 significantly increased the linear index and Fraction 4 significantly increased the progressiveness ratio and curvilinear progressiveness ratio in both strains, as compared to both BSA and no protein. While none of the fractions altered the curvilinear velocity in both strains, Fraction 2 increased the 
Table 1. The effects of fractionated seminal vesicle proteins on mouse sperm motility and velocity

\begin{tabular}{|c|c|c|c|c|c|}
\hline Strain & Treatment & $\begin{array}{l}\text { Protein conc. } \\
\qquad(\mathrm{mg} / \mathrm{ml})\end{array}$ & $\begin{array}{c}\% \\
\text { Motility }\end{array}$ & $\begin{array}{l}\text { Curvilinear } \\
\text { velocity }(\mathrm{Vc}) \\
(\mu \mathrm{m} / \mathrm{sec})\end{array}$ & $\begin{array}{l}\text { Coefficient of } \\
\text { variation of } \\
\text { move length } \\
\text { (CVML) }\end{array}$ \\
\hline Hybrid & Fraction 1 & $0.98 \pm 0.35$ & $25 \cdot 9 \pm 8 \cdot 7$ & $\begin{array}{c}244 \pm 5 \cdot 5 \\
(247,167-357)\end{array}$ & $\begin{array}{c}49 \cdot 1 \pm 1 \cdot 0^{\mathrm{a}} \\
(49 \cdot 4,32 \cdot 2-67 \cdot 5)\end{array}$ \\
\hline Hybrid & Fraction 2 & $0.24 \pm 0.03$ & $36 \cdot 2 \pm 6 \cdot 2$ & $\begin{array}{r}263 \pm 5 \cdot 2^{a, b} \\
(262,192-386)\end{array}$ & $\begin{array}{c}51 \cdot 0 \pm 1 \cdot 0 \\
(50 \cdot 0,32 \cdot 5-69 \cdot 4)\end{array}$ \\
\hline Hybrid & Fraction 3 & $0 \cdot 10 \pm 0 \cdot 01$ & $7 \cdot 7 \pm 2 \cdot 5^{a, b}$ & - & - \\
\hline Hybrid & Fraction 4 & $0.21 \pm 0.03$ & $39 \cdot 8 \pm 6 \cdot 3$ & $\begin{array}{c}249 \pm 4 \cdot 9^{b} \\
(245,162-343)\end{array}$ & $\begin{array}{c}46 \cdot 1 \pm 1 \cdot 0^{\mathrm{a}, \mathrm{b}} \\
(46 \cdot 3,21 \cdot 8-63 \cdot 8)\end{array}$ \\
\hline Hybrid & BSA & 1 & $58 \cdot 6 \pm 4 \cdot 3$ & $\begin{array}{c}233 \pm 5 \cdot 2 \\
(232,132-352)\end{array}$ & $\begin{array}{c}51 \cdot 8 \pm 1 \cdot 0 \\
(51 \cdot 6,32 \cdot 1-75 \cdot 6)\end{array}$ \\
\hline Hybrid & No protein & - & $50 \cdot 5 \pm 6 \cdot 1$ & $\begin{array}{c}238 \pm 4 \cdot 9 \\
(236,146-350)\end{array}$ & $\begin{array}{c}52 \cdot 3 \pm 1 \cdot 2 \\
(52 \cdot 6,29 \cdot 7-72 \cdot 3)\end{array}$ \\
\hline Outbred & Fraction 1 & $0.95 \pm 0.23$ & $16 \cdot 6 \pm 2 \cdot 9$ & $\begin{array}{c}233 \pm 6 \cdot 3 \\
(241,95-325)\end{array}$ & $\begin{array}{c}46 \cdot 3 \pm 1 \cdot 2^{b} \\
(46 \cdot 7,28 \cdot 1-79 \cdot 6)\end{array}$ \\
\hline Outbred & Fraction 2 & $0.45 \pm 0.08$ & $17 \cdot 3 \pm 3 \cdot 4$ & $\begin{array}{c}251 \pm 5 \cdot 7 \\
(259 \cdot 5,91-342)\end{array}$ & $\begin{array}{c}42 \cdot 7 \pm 1 \cdot 0^{\mathrm{a}, \mathrm{b}} \\
(42 \cdot 4,23 \cdot 0-65 \cdot 0)\end{array}$ \\
\hline Outbred & Fraction 3 & $0.30 \pm 0.12$ & $8 \cdot 7 \pm 2 \cdot 5^{a, b}$ & - & - \\
\hline Outbred & Fraction 4 & $0 \cdot 38 \pm 0 \cdot 1$ & $17 \cdot 5 \pm 1 \cdot 8$ & $\begin{array}{c}221 \pm 8 \cdot 1 \\
(236,88-333)\end{array}$ & $\begin{array}{c}47.5 \pm 1 \cdot 4 \\
(46 \cdot 6,30 \cdot 0-87 \cdot 2)\end{array}$ \\
\hline Outbred & BSA & 1 & $25 \cdot 1 \pm 2 \cdot 4$ & $\begin{array}{c}251 \pm 5 \cdot 6 \\
(240,178-375)\end{array}$ & $\begin{array}{c}49 \cdot 9 \pm 1 \cdot 0 \\
(50 \cdot 5,35 \cdot 4-67 \cdot 3)\end{array}$ \\
\hline Outbred & No protein & - & $29 \cdot 9 \pm 3 \cdot 7$ & $\begin{array}{c}242 \pm 5 \cdot 4 \\
(246,137-327)\end{array}$ & $\begin{array}{c}47.6 \pm 1 \cdot 3 \\
(47 \cdot 2,25 \cdot 6 \quad 67 \cdot 4)\end{array}$ \\
\hline Outbred & $\begin{array}{l}\text { Mixed } \\
\text { fractions }\end{array}$ & & $15 \cdot 7 \pm 2 \cdot 8$ & $\begin{array}{c}238 \pm 9 \cdot 6 \\
(255,103-310)\end{array}$ & $\begin{array}{c}42 \cdot 2 \pm 1 \cdot 0^{\mathrm{a} \cdot \mathrm{b}} \\
(41 \cdot 0,32 \cdot 0-59 \cdot 3)\end{array}$ \\
\hline
\end{tabular}

Values are mean \pm s.e.m. (median and range) for 4 columns for each individual fraction and the mixed fractions were tested for 3 columns.

Bold values differ significantly from both BSA and no protein controls in both strains of mice.

${ }^{2}$ Significantly different from no protein, $P<0.05$.

'Significantly different from BSA, $P<0.05$.

velocity of spermatozoa from hybrid males. There were also other obvious differences between the spermatozoa from the two strains. All the spermatozoa from outbred mice had higher PRc values than those from the hybrid animals and only the spermatozoa incubated without the addition of protein were not significantly higher. This indicates that in general the outbred spermatozoa show less side-to-side oscillation. Other significant differences between the two strains were seen in their response to incubation in proteins. Spermatozoa of outbred mice showed no effect of incubation in BSA and had significantly higher LI, PRc and PR values than did spermatozoa from hybrid mice, incubated with BSA. Fraction 1 had no significant effects on spermatozoa from outbred mice but increased LI and PR in the hybrid strain. In the outbred strain Fraction 2 affected most of the motility measures while Fraction 4 was most effective in the hybrids. Spermatozoa of outbred mice showed more pronounced effects of incubation in Fraction 2 and had significantly higher values for LI, PR and PRc and lower CVML values than did the spermatozoa from hybrid mice. The apparent difference in response to Fraction 2 between strains may be due to the higher concentration of Fraction 2 recovered from outbred animals.

The results of incubating spermatozoa in a solution prepared by mixing equal volumes of each of the 4 fractions can be seen in Tables 1 and 2 . The mixed proteins cause changes in motility 
Table 2. The effects of fractionated seminal vesicle proteins on the path shape measures for mouse spermatozoa

\begin{tabular}{|c|c|c|c|c|}
\hline Strain & Treatment & $\begin{array}{c}\text { Linear } \\
\text { index (LI) }\end{array}$ & $\begin{array}{l}\text { Curvilinear } \\
\text { progressiveness } \\
\text { ratio (PRc) }\end{array}$ & $\begin{array}{l}\text { Progressiveness } \\
\text { ratio (PR) }\end{array}$ \\
\hline Hybrid & Fraction 1 & $\begin{array}{c}0.911 \pm 0.013^{\mathrm{a} . \mathrm{b}} \\
(0.935,0.192-0.981)\end{array}$ & $\begin{array}{c}0.618 \pm 0.013^{\mathrm{b}} \\
(0.548,0.403-0.879)\end{array}$ & $\begin{array}{r}0.566 \pm 0.016^{\text {a.b }} \\
(0.560,0 \cdot 106-0.805)\end{array}$ \\
\hline Hybrid & Fraction 2 & 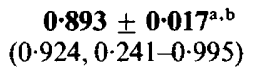 & $\begin{array}{c}0.589 \pm 0.010^{\mathrm{b}} \\
(0.586,0.425-0.797)\end{array}$ & $\begin{array}{c}0.529 \pm 0.016 \\
(0.537,0.124-0.781)\end{array}$ \\
\hline Hybrid & Fraction 4 & $\begin{array}{c}0.941 \pm 0.005^{\mathrm{a}, \mathrm{b}} \\
(0.948,0.835-1.000)\end{array}$ & $\begin{array}{c}\mathbf{0 . 6 5 2} \pm \mathbf{0 \cdot 0 1 5 ^ { \text { a.b } }} \\
(0.640,0.427-0.897)\end{array}$ & $\begin{array}{c}\mathbf{0 . 6 1 6} \pm \mathbf{0 . 0 1 6}^{\mathbf{a . b}} \\
(0.612,0 \cdot 375-0.838)\end{array}$ \\
\hline Hybrid & BSA & $\begin{array}{c}0.654 \pm 0.038^{\mathrm{a}} \\
(0.735,0.069-0.981)\end{array}$ & $\begin{array}{c}0.522 \pm 0.013^{\mathrm{a}} \\
(0.510,0 \cdot 303-0.810)\end{array}$ & $\begin{array}{c}0 \cdot 360 \pm 0 \cdot 026^{\mathrm{a}} \\
(0 \cdot 358,0 \cdot 026-0 \cdot 765)\end{array}$ \\
\hline Hybrid & No protein & $\begin{array}{c}0.827 \pm 0.023 \\
(0.902,0.354-0.997)\end{array}$ & $\begin{array}{c}0.601 \pm 0.014 \\
(0.580,0.426-0.880)\end{array}$ & $\begin{array}{c}0.508 \pm 0.022 \\
(0.528,0 \cdot 152-0.869)\end{array}$ \\
\hline Outbred & Fraction 1 & $\begin{array}{c}0.913 \pm 0.013^{\mathrm{b}} \\
(0.945,0.5300 .993)\end{array}$ & $\begin{array}{c}0.671 \pm 0.015^{\mathrm{b}} \\
(0.670,0.3700 .882)\end{array}$ & $\begin{array}{c}0.619 \pm 0.018^{\mathrm{b}} \\
(0.633,0.223-0.833)\end{array}$ \\
\hline Outbred & Fraction 2 & $\begin{array}{c}\mathbf{0 \cdot 9 2 0} \pm \mathbf{0 \cdot 0 1 9 ^ { \mathrm { a } , \mathrm { b } }} \\
(0 \cdot 964,0 \cdot 076-1 \cdot 000)\end{array}$ & $\begin{array}{c}0.696 \pm 0.013^{\mathrm{a}, \mathrm{b}} \\
(0.704,0.484-0.910)\end{array}$ & $\begin{array}{c}0.648 \pm 0.020^{\mathrm{a}, \mathrm{b}} \\
(0.666,0.037-0.880)\end{array}$ \\
\hline Outbred & Fraction 4 & $\begin{array}{c}0.902 \pm 0.017^{\mathrm{b}} \\
(0.938,0.277-0.983)\end{array}$ & $\begin{array}{c}\mathbf{0 \cdot 7 0 2} \pm \mathbf{0 \cdot 0 1 7 ^ { \mathrm { a } , \mathrm { b } }} \\
(0 \cdot 725,0 \cdot 358-0 \cdot 927)\end{array}$ & $\begin{array}{r}\mathbf{0 . 6 4 0} \pm \mathbf{0 . 0 2 2 ^ { \mathbf { a } , \mathbf { b } }} \\
(0.611,0.037-0.880)\end{array}$ \\
\hline Outbred & BSA & $\begin{array}{c}0.805 \pm 0.031 \\
(0.924,0.074-0.988)\end{array}$ & $\begin{array}{c}0.605 \pm 0.012 \\
(0.588,0.360-0.826)\end{array}$ & $\begin{array}{c}0.499 \pm 0.024 \\
(0.522,0.036-0.810)\end{array}$ \\
\hline Outbred & No protein & $\begin{array}{c}0.822 \pm 0.031 \\
(0.934,0.024-1 \cdot 000)\end{array}$ & $\begin{array}{c}0.637 \pm 0.017 \\
(0.630,0.389-0.911)\end{array}$ & $\begin{array}{c}0.540 \pm 0.028 \\
(0.582,0.011-0.897)\end{array}$ \\
\hline Outbred & $\begin{array}{l}\text { Mixed } \\
\text { fractions }\end{array}$ & $\begin{array}{c}0.936 \pm 0.013^{\mathrm{a}, \mathrm{b}} \\
(0.961,0.594-1 \cdot 000)\end{array}$ & $\begin{array}{c}0.711 \pm 0.015^{\mathrm{a} . \mathrm{b}} \\
(0.697,0.506-0.905)\end{array}$ & $\begin{array}{r}0.668 \pm 0.018^{\text {a,b }} \\
(0.663,0 \cdot 301-0.842)\end{array}$ \\
\hline
\end{tabular}

Values are mean \pm s.e.m. (median and range) for 4 columns for each individual fraction and the mixed fractions were tested for 3 columns.

Bold values differ significantly from both BSA and no protein controls in both strains of mice.

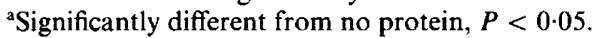

'Significantly different from BSA, $P<0.05$.

measures similar to those seen with Fraction 2 . The percentage motility, while decreased as compared to BSA, was still significantly higher than motility in Fraction 3 alone. This indicates that the motility-inhibiting factors in Fraction 3 are diluted by mixing with the other fractions or the other fractions are able to protect the spermatozoa from the inhibition. In either case it seems unlikely that the motility-inhibiting effect would be detectable in unfractionated seminal plasma.

Correlation coefficients were calculated for the relationship between the protein concentration and percentage motility from Fractions 2, 3 and 4 and between the protein concentration and the motility measures for Fractions 2 and 4. Since Fraction 1 had no significant effects common to both strains no correlations were calculated for this fraction. The non-parametric Spearman's Rank Correlation test was used. None of these correlation coefficients was statistically significant. The lack of a significant correlation between the motility measures and the protein concentration was most probably due to the narrow range of concentrations tested. For Fraction 4 the range was only from 0.13 to $0.6 \mathrm{mg} / \mathrm{ml}$, not even a 5 -fold difference. The range for Fraction 2 was from 0.147 to $0.645 \mathrm{mg} / \mathrm{ml}$ and for Fraction 3, 0.075 to $0.247 \mathrm{mg} / \mathrm{ml}$.

\section{Discussion}

The results in this paper demonstrate that the seminal vesicle fluid of the house mouse can be fractionated to yield several fractions which influence sperm motility. These fractions have different 
effects. One of the fractions inhibits motility while two other fractions influence the pattern of the swimming motion of spermatozoa. The composition of these fractions has not yet been determined but each fraction obviously contains many proteins. Further separation of the active fractions by ion exchange or affinity binding gels may help to isolate individual proteins which influence sperm motility.

Seminal vesicle Fraction 3 inhibited motility. After incubation for $2 \mathrm{~h}$ very few motile spermatozoa were found and no estimate of any of the motility measures could be obtained. The way in which Fraction 3 interacts with spermatozoa to inhibit motility has not been determined. High viscoelasticity inhibits sperm motility in the cauda epididymidis in a number of rodents (Turner \& Reich, 1985). However, it is unlikely that the same effect is responsible for the motility inhibition shown by Fraction 3 since the concentrations at which it showed inhibition $(0.3 \pm 0.1 \mathrm{mg} / \mathrm{ml}$ for outbred mice and $0.1 \pm 0.01 \mathrm{mg} / \mathrm{ml}$ for hybrid mice) are much lower than the typical protein concentration reported for epididymal fluid $(28.5 \mu \mathrm{g} / \mu \mathrm{l}$ for the rat; Turner \& Reich, 1985). In addition, the molecular weight range of Fraction 3 (12000-24 000) is much lower than that reported for rat immobilin $\left(M_{\mathrm{r}}>200000\right.$ : Usselman \& Cone, 1983).

Fraction 2 increased the linear index (LI) in both strains while Fraction 4 significantly increased the progressiveness ratio $(\mathrm{PR})$ and curvilinear progressiveness ratio $(\mathrm{PRc})$ of spermatozoa from mice of both strains. Spermatozoa incubated in Fraction 2 therefore swim with straighter trajectories while those incubated in Fraction 4 swim in straighter paths with less side-to-side movement of the head about the path. These fractions therefore appear to be affecting different aspects of the pattern or shape of sperm movement. The relationship of this straight pattern of motility to other types of motility described for mouse spermatozoa, including hyperactivation, has not been determined. The effects of Fractions 2 and 4 are probably not simply inhibition of hyperactivation because spermatozoa incubated in Fractions 2 and 4 had motility values significantly different from those of spermatozoa incubated in media with no added protein. Since Ward \& Storey (1984) have demonstrated that BSA is necessary for capacitation and hyperactivation in vitro, and BSA was not added to the media used to test the seminal vesicle fractions, it is unlikely that these spermatozoa were capacitated. Tests of the effects of the seminal vesicle fractions on spermatozoa which have been capacitated in the presence of BSA have not yet been performed.

The values for LI, PR and PRc of epididymal spermatozoa incubated in Fraction 2 and Fraction 4 are similar to the LI, PR and PRc values of uterine spermatozoa from normal matings and much higher than LI, PR and PRc values of uterine spermatozoa from matings with males with extirpated seminal vesicles (Peitz \& Olds-Clarke, 1986). The absence of these factors therefore probably accounts for the differences in sperm motility seen after seminal vesicle removal. Seminal plasma also influences the progressiveness of spermatozoa from other species. Progressiveness increased when seminal plasma was added to human epididymal or washed ejaculated spermatozoa (Lindholmer, 1974). Removal of human spermatozoa from the seminal plasma by the swim-up method led to an increase in the percentage of non-progressive spermatozoa and an increase in the amplitude of side-to-side head movements in the progressively swimming spermatozoa as measured from photographs produced by the multiple exposure photographic method (Mortimer et al., 1984). Washing ejaculated boar spermatozoa also led to an increase in the apparent side-to-side motions and addition of seminal plasma to washed boar spermatozoa enhanced progressive motility as measured by the ability of the spermatozoa to swim up a capillary tube (Tso \& Lee, 1980). Three fractions that could increase progressive motility were recovered following fractionation of human seminal plasma on Sephadex G200 (Stegmayr \& Ronquist, 1982). Thus, in many species, the accessory glands produce factors which increase the progressive motility of spermatozoa.

In this study Fraction 3 was the only fraction that significantly altered the percentage motility and the effects of the other fractions would not have been detected without examining the swimming pattern. The use of a videomicrographic system to examine sperm movement and analyse the swimming pattern of progressive and non-progressive spermatozoa has made it 
possible to detect changes in the type of sperm motility that would not have been recognized if only the percentage motility had been determined.

None of the fractions showed any effect on sperm curvilinear velocity in either mouse strain. Multiplying the curvilinear velocity by the progressiveness ratio in Tables 1 and 2 to calculate the net velocity indicates that the net velocity of mouse spermatozoa was also unaffected by seminal vesicle fractions. However, semen is reported to decrease net velocity of spermatozoa in a number of other species since washing, diluting, or separating the ejaculated spermatozoa from seminal plasma by the swim-up method causes the net velocity to increase for human (Cohen et al., 1981; Katz \& Overstreet, 1981; Mortimer et al., 1984) and bull (Katz \& Overstreet, 1981) spermatozoa. If a factor that reduces net velocity is present in mouse semen it must be produced by one of the other accessory glands since the seminal vesicle fractions did not have this effect. Alternatively, the reduced net velocity of spermatozoa in whole human semen may be due to viscosity effects caused by the density of the spermatozoa and the total concentration of protein rather than being a specific effect of any one protein in the semen.

While some differences in response to seminal vesicle fractions and BSA were noted between the two mouse strains used in this study, the significance of these differences is unclear since only 4 males of each of the 2 strains were tested. However, further studies of the differences in motility between strains may be warranted since the success of in-vitro fertilization has also been shown to vary between strains (Parkening \& Chang, 1976).

The significance of the effects of these fractions on motility for fertility is not known. Although motility is necessary for fertility, the aspects of motility needed are unclear. In addition, the motility pattern differs in different species. In the house mouse low sperm progressiveness has been associated with reduced fertility after matings with males from which the seminal vesicles had been removed (Peitz \& Olds-Clarke, 1986) and with sterility of males heterozygous for two t haplotypes (Olds-Clarke, 1986). Seminal factors which improve sperm progressiveness may therefore promote fertility in the house mouse.

Influences of seminal plasma factors on sperm motility are often disregarded because spermatozoa are assumed to remain in contact with the seminal plasma for a very short time after natural mating since the bulk of the seminal plasma does not enter the uterus. However, proteinase inhibitors, produced in the seminal vesicles, are known to bind to the spermatozoa at ejaculation (Irwin et al., 1983; Fritz et al., 1976) and have been identified in the uterus for up to $10 \mathrm{~h}$ after mating in the mouse (Nicholson et al., 1983). Other seminal plasma constituents also pass through the female reproductive tract with the spermatozoa. In rats, zinc, from the prostate, was detected in the uterus and oviducts after mating (Gunn \& Gould, 1958). Thus seminal factors may play a more important role in fertility following natural mating than has been recognized. In addition, the action of seminal plasma factors may have important effects in artificial insemination or in-vitro fertilization protocols in which semen samples are collected and allowed to liquefy before separating the spermatozoa from the seminal plasma. Cohen et al. (1981) demonstrated that the motility of human spermatozoa from semen samples that were collected into incubation medium was different from the motility of those from semen which was collected without dilution and allowed to liquefy before removing the seminal plasma.

These studies make it clear that the seminal vesicle components have a direct effect on sperm motility that is independent of the uterine environment or the secretions of other accessory glands. In addition, the influence of these factors on sperm motility in vitro is similar to that noted for the seminal vesicle fluid in vivo (Peitz \& Olds-Clarke, 1986). Seminal vesicle fluid can therefore be fractionated into several components with discrete effects that can be studied in vitro and this study provides the starting point for the isolation of individual seminal vesicle components that control sperm motility.

This study was done while the author was on leave in the Anatomy Department at Temple 
University School of Medicine, Philadelphia, PA 19140, in the laboratory of Dr P. Olds-Clarke and was supported by NIH grant HD15045 and a grant from the Mellon Foundation to P.O.-C.

Supported in part by NIH-MARC Faculty Fellowship GM 09468 and NIH grant RR08101 to B.P.

\section{References}

Baas, J.W., Molan, P.C. \& Shannon, P. (1983) Factors in seminal plasma of bulls that affect the viability and motility of spermatozoa. J, Reprod. Fert. 69, 275-280.

Cohen, J., Euser, R., Schenck, P.E., Brugman, F.W. \& Zeilmaker, G.H. (1981) Motility and morphology of human spermatozoa in split ejaculates. Andrologia 13, 49 [- 498 .

Cohen, J., Mooyaart, M., Vreeburg, J.T.M., Yanagimachi, R. \& Zeilmaker, G.H. (1982) Fertilizing ability and motility of spermatozoa from fertile and infertile men after exposure to heterologous seminal plasma. In Instrumental Insemination, pp. 54-62. Eds E. S. E. Hafez \& K. Semm. Martinus Nijhoff Publishers, The Hague.

Dott, H.M., Harrison, R.A.P. \& Foster, G.C.A. (1979) The maintenance of motility and the surface properties of epididymal spermatozoa from bull, rabbit and ram in homologous seminal and epididymal plasma. J. Reprod. Fert. 55, 113-124.

Fritz, H., Schleuning, W.D., Schiessler, H., Schill, W.B. \& Wendt, V. (1976) Seminal proteinase inhibitors and sperm acrosin: Biochemistry and possible functions. In Human Semen and Fertility Regulation in Men, pp 201-216. Ed. E. S. E. Hafez. C. V. Mosby, St Louis.

Gunn, S.A. \& Gould, T.C. (1958) Role of zinc in fertility and fecundity in the rat. Am. J. Physiol. 193, 505-508

Irwin, M., Nicholson, N., Haywood, J.T. \& Poirier, G.R. (1983) Immunofluorescent localization of a murine seminal vesicle proteinase inhibitor. Biol. Reprod. 28, 1201-1206.

Katz, D.F. \& Overstreet, J.W. (1981) Sperm motility assessment by videomicrography. Fert. Steril. 35, 188-193.

Lindholmer, C. (1974) The importance of seminal plasma for human sperm motility. Biol. Reprod. 10, 533-542.

Mann, T. \& Lutwak-Mann, C. (1981) Male Reproductive Function and Semen. Springer-Verlag, Berlin.

Morita, Z. \& Chang, M.C. (1971) Maintenance of the motility of rat epididymal spermatozoa in the pres. ence of male accessory secretions. J. Reprod. Fert. 24, $247-254$

Mortimer, D., Courtot, A.M., Giovangrandi, Y., Jeulin, C. \& David, G. (1984) Human sperm after migration into and incubation in, synthetic media. Gamete $R s$. 9, 131-144.

Nicholson, N., Irwin, M. \& Poirier, G.R. (1983) Immunofluorescent localization of a seminal vesicle proteinase inhibitor in the female reproductive tract of naturally inseminated mice. J. exp. Zool. 225, 481-487.

Olds-Clarke, P. (1986) Motility characteristics of sperm from the uterus and oviducts of female mice after mating to congenic males differing in sperm transport and fertility. Biol. Reprod. 34, 453-467.

Overstreet, J.W., Katz, D.F., Hanson, F.W. \& Fonesca, J.R. (1979) A simple inexpensive method for objective assessment of human sperm movement characteristics. Fert. Steril. 31, 162-172.

Pang, S.F., Chow, P.H. \& Wong, T.M. (1979) The role of the seminal vesicles, coagulating glands and prostate glands on the fertility and fecundity of mice. $J$. Reprod. Fert. 56, 129-132.

Parkening, T.A. \& Chang, M.C. (1976) Strain differences in the in vitro fertilizing capacity of mouse spermatozoa as tested in various media. Biol. Reprod. 15, $647-653$.

Peitz, B. \& Bennett, D. (1981) Inhibition of complementmediated cytotoxicity of antisera by fluid secreted by the seminal vesicle of the house mouse. J. Reprod. Immunology 3, 109-116.

Peitz, B. \& Olds-Clarke, P. (1986) Effects of seminal vesicle removal on fertility and uterine sperm motility in the house mouse. Biol. Reprod. 35, 608-617.

Queen, K., Dhabuwala, C.B. \& Pierrepoint, C.G. (1981) The effect of the removal of the various accessory sex glands on the fertility of male rats. J. Reprod. Fert. 62, 423-426.

Rozin, S. (1960) Studies on seminal plasma. I. The role of seminal plasma in motility of spermatozoa. Fert. Steril. 11, 278-285.

Sokal, R.R. \& Rohlf, F.J. (1969) Biometry. W. H. Freeman, San Francisco.

Stegmayr, B. \& Ronquist, G. (1982) Promotive effect on human sperm progressive motility by prostasomes. Urological Res. 10, 253-257.

Tessler, S. \& Olds-Clarke, P. (1985) Linear and nonlinear mouse sperm motility patterns. J. Androl. 6, 35-44.

Tso, W.W. \& Lee, W.M. (1980) Seminal plasma and progressive motility of boar spermatozoa. Int. J. Androl. 3, 243-250

Turner, T.T. \& Reich, G.W. (1985) Cauda epididymal sperm motility: a comparison among five species. Biol. Reprod. 32, 120-128.

Usselman, M.C. \& Cone, R.A. (1983) Rat sperm are mechanically immobilized in the cauda epididymidis by "Immobilin" a high molecular weight glycoprotein. Biol. Reprod. 29, 1241-1253.

Ward, C.R. \& Storey, B.T. (1984) Determination of the time course of capacitation in mouse spermatozoa using a chlortetracycline fluorescence assay. Devl Biol. 104, 287-296. 